\title{
A Study on Listening Strategies Instructed by Teachers and Strategies Used by Students
}

\author{
Xiaoli Bao ${ }^{1}$ \\ ${ }^{1}$ School of Foreign Language, Inner Mongolia University for Nationalities, Tongliao, Inner Mongolia, China \\ Correspondence: Xiaoli Bao, School of Foreign Language, Inner Mongolia University for Nationalities, Tongliao, \\ Inner Mongolia, China. E-mail: nmbaoxiaoli@163.com
}

\author{
Received: February 3, 2017 Accepted: February 24, 2017 Online Published: February 26, 2017 \\ doi:10.5539/ijel.v7n2p186 URL: http://doi.org/10.5539/ijel.v7n2p186
}

\begin{abstract}
Listening strategy is one of the most important factors that affect the process of listening comprehension. This article makes an empirical study on the listening strategies used by 174 non-English majors and 35 college English teachers. It aims at finding out how students use and teachers teach listening strategies, making comparison and contrast between teachers and students in using listening strategies, and recommending some constructive suggestions related to listening activities.
\end{abstract}

Keywords: listening strategies, teachers and students, empirical study, difference

\section{Introduction}

The improvement of English listening comprehension depends on many factors. Through the study of listening comprehension strategies, the author tries to help learners improve their listening level. The author has consulted literature materials so far and found there are not too many scholars that specialize in studying listening strategies at home and abroad, especially in China. Scholars did publish some articles of empirical study in journals home and abroad but the number of these articles the author can find is small and these articles study the listening strategies only from the perspective of students. The number of the articles studying the listening strategies from both teachers and students is small. Therefore, the author hopes this study can make up for any deficiencies above. Through the comparison study of students and teachers' application of listening strategies, the author provides some data and gives some suggestions on the application of listening strategies from the perspective of both teachers and students in order to improve non-English majors' listening teaching.

\section{Theory}

\subsection{The Mircro-process of Listening}

Coordinating all the work indispensable to achieve listening comprehension involves a great deal of activities on the part of the listener. Anderson $(1983,1985)$ differentiates listening comprehension into three interrelated and recursive process: perceptual processing, parsing, and utilization. During a single listening event, the process may flow one into the other and recycle, and may be modified based on what occurs in prior or subsequent processes.

Perceptual processing is the first stage of information processing. It is the encoding of the acoustic or written message. In listening this involves segmenting phonemes from the continuous speech stream (Anderson, 1985). In the perceptual processing, listeners' attention focuses mainly on the listening materials. They discriminate the sounds, words and sentences, at the same time, store them in short-term memory. During this process, attention may be directed selectively to some special aspects of the task or the context that will be more useful in comprehension. In listening, these aspects might include pauses and acoustic emphasis that provide clues to segmentation (O'Malley \& Chamot, 1990). In perceptual processing, the capacity limitations of sensory stores prevent specific word sequences from being retained longer than a few seconds, and new information replaces former information almost immediately. As a result, attention must be directed selectively to the context that will be useful in comprehension or aspects of the task which might be phonological features of the message, such as pauses and acoustic emphases that provide clues to segmentation. And sounds perceived are temporarily stored in sensory stores.

In the second phase of listening comprehension, parsing, the sounds stored in sensory stores are segmented into 
words, phrases, clauses or other linguistic units which are used to construct meaningful mental representations. Listeners try to match words that are heard with a type of dictionary in permanent memory that enables us to identify the meanings of individual words. Somehow the context limits the amount of metal space that has to be searched to get the right meaning. That is, the context automatically makes particular meanings of words available to us. Variations in the amount of information retained in permanent memory, the way in which that information is organized and the access listeners have to that information all contribute to different abilities in listening comprehension.

The third stage, utilization, consists of relating the information heard to existing knowledge, which will assist in interpreting the text's meaning. Existing knowledge is stored in permanent memory in propositions and in schemata, which is activated to the degree that it is related to the new information in working memory so that when input and knowledge are matched against each other, comprehension takes place.

We may also put the three stages of listening comprehension process another way, first we identify the given new information, we then find an antecedent in memory related to the given information, and finally we attach the new information to this spot in memory. In a word, listening comprehension entails a lot of complex mental work with many factors having a hand in it, which serve either to detract from or to facilitate the listener's second language comprehension.

\subsection{Definition and Classification of Listening Strategies}

Western study of second languagelforeign language listening comprehension strategies regards learning strategies as its theoretical framework, therefore many scholars consider listening comprehension strategies as learning strategies. As for the definition of learning strategies in the literature, there are no universally agreed point of views. Different scholars give different definition from different angles. Chatom (1987) points out that learning strategy are techniques, approaches or deliberate actions that students take in order to facilitate learning and recall of both linguistic and content area information. Oxford (1990) defines language learning strategy as conscious step or behaviors used by language learners to enhance the acquisition, storage, retention, recall, and use of information. Ellis (1994) points out a strategy, which consists of mental or behavioral activity relates to some specific stage in the overall process of language acquisition or language use.

According to him, learning strategy has the following characteristics:

1) Strategies refer to both general approaches and specific actions or techniques used to learn a L2.

2) Strategies are problem-oriented - the learner deploys a strategy to overcome some particular learning problems.

3) Learners are generally aware of the strategies they use and can identify what they consist of if they are asked to pay attention to what they are doing/thinking.

4) Strategies involve linguistic behavior and non-linguistic behavior.

5) Linguistic strategies can be performed in the $\mathrm{L} 1$ and in the $\mathrm{L} 2$.

6) Some strategies are behavioral while others are mental. Thus some strategies are directly observable, while others are not.

7) Strategies contribute indirectly or directly to learning by providing learners with data about the L2 which they can then process.

8) Strategies use varies considerably as a result of both the kind of task the learner is engaged in and individual learner preferences.

According to O'Malley \& Chamot, three major types of strategy are distinguished in accordance with the information-processing model; cognitive strategies, meta-cognitive strategies and social/affective strategies. Cognitive strategies refer to the steps or operations used in problem-solving that require direct analysis, transformation or synthesis of learning materials (Rubin, 1981). Generally, cognitive strategies operate directly on incoming information, manipulating it in ways that enhance learning, while they may be limited in application to the specific type of task in the learning activity. Typical cognitive strategies for listening comprehension include rehearsal, organization, inferencing, summarizing, deduction, imagery, transfer, elaboration etc. Meta-cognitive strategies are higher order executive skills that may entail planning for, monitoring, or evaluating the success of learning activities (Brown et al., 1983). Meta-cognitive strategies are applicable to a variety of learning tasks (Nisbet \& Shucksmith, 1986). Advanced meta-cognitive learners make a general but comprehensive preview of the concept or principle in an anticipated learning activity and decide in advance to attend in general to a learning task and to ignore irrelevant distractions (O'Malley \& Chamot, 1990). 
Meta-cognitive strategies for receptive or productive language tasks include selective attention, planning, monitoring, evaluation etc. Social/affective strategies concern the ways in which learners interact with other learners and native speakers. They represent a broad grouping that involves either interaction with another person or ideational control over affect. Cooperation, self-questioning, and self-talk are the typical social/affective strategies.

Based on O'Malley's \& Chamot's (1990) listening strategies and combined with the unique characteristics of listening comprehension process, the author summed up a set of listening strategies, which is mainly divided into three categories, that is, cognitive strategies, meta-cognitive strategies and social/affective strategies. They are subdivided into 31 strategies: language awareness, advanced preparation, directed attention, selective attention, self-management, self-monitoring, self-assessment, utilization of resources, repetition, induction, deductive reasoning, analysis, imagination, hearing recurrence, using the key words, connection between old and new knowledge, migration, reasoning, note-taking, summary, restructuring, translation, identifying and using the fixed language collocation, listening to real corpora, cultivating interest, relieving anxiety, encouraging yourself, exchanging position, clarifying issues, cooperative learning.

Through the above the definition and classification of listening strategies, we can see that strategy is the decision the listeners make and the specific methods and behaviors the listeners adopt in order to listen effectively and comprehensively.

\section{Methods}

By random sampling, the author made a questionnaire survey on 174 non-English majors and 35 teachers of College English Department in a University and recycled 170 and 34 effective questionnaires respectively.

The research instruments are two kinds of questionnaires: students' listening strategy questionnaires and teachers' listening strategy questionnaires. The contents of the two questionnaires are broadly similar but the methods of questionnaire are different. The questionnaire includes two parts: the first part is the background questionnaire, the second part is the listening strategy questionnaire. The questionnaire uses five level methods.

This study adopts the method of questionnaire survey and makes the SPSS statistical analysis of the data. All the conclusions are based on the data. The study mainly investigates the following five questions:

1) What is overall situation of non-English majors' application of listening strategies?

2) What are the strategies the students commonly use and seldom use?

3) What is the overall situation of teachers' instructing listening strategies?

4) What are the strategies teachers often instruct and what are the strategies teachers often neglect?

5) What is relationship between the strategies teachers instruct and the strategies the students use?

\section{Findings and Discussion}

\subsection{Students' Strategies}

\subsubsection{The Overall Situation of Students' Using Listening Strategies}

Table 1. The overall situation of students' using listening strategies

\begin{tabular}{lll}
\hline Types of Strategies & Mean Value & Standard Deviation \\
\hline meta-cognitive strategies & 2.2333 & .42981 \\
cognitive strategies & 3.0354 & .40227 \\
social/affective strategies & 2.6949 & .54748 \\
overall strategies & 2.9449 & .38414 \\
\hline
\end{tabular}

In general, the frequency of students' using listening strategies is not high, it stays in medium level. The frequency of utilizing the strategies from high to low is cognitive strategies, metacognitive strategies and social laffective strategies. The author analyzes and finds out that the low frequency is related to the concept of learning. Learners' language learning concept is the key factor for them to decide on the application of listening strategies. As can be seen from the questionnaire survey, more than $50 \%$ of the students surveyed think that good foreign language learners have language talent. The strength of this concept is bound to affect students' learning motivation, which may lead to the result that in the process of listening students seldom use the listening strategies to improve their listening level. Oddly enough, more than $97 \%$ of the students think choose effective 
listening method is very important to improve their listening level. Thus the concept of students' language learning is contradictory and conflict. On one hand, they believe that language talent is very important, on the other hand, they also think efforts are important. This contradictive concept of learning determines the frequency of the strategy they use is not too high or too low, but only in the medium level. In addition, previous studies have indicated that Chinese high school students' application of learning strategies is not high, the total average scores are 2.76 (Zhang, 1998). The research subjects of this research are first-first undergraduate students. They can't avoid being affected by learning strategies and learning styles of their high school experiences.

\subsubsection{The Commonly Used Listening Strategies and the Seldom Used Listening Strategies}

In order to further investigate students' application of learning strategies. Based on the students' questionnaire the author lists the mean value of students' application of strategies from high to low. The result of the order shows the four high strategies students use are separately: reasoning $(32,33,34)$, the mean value is 3.81 ; self-monitoring $(16,17), 3.76$; the connection between old and new knowledge $(29,30), 3.69$; the migration (31), 3.67. And the use of keywords (28), cooperative learning $(50,51)$, translation $(39)$, question clarification $(48,49)$ and language awareness $(1,2,3,4,5)$, these five strategies are often neglected by students, the mean value is $1.84,2.0,2.31,2.41,2.47$ respectively.

From the analysis we conclude that self-monitoring strategy $(16,17)$ which belongs to metacognitive is frequently used by students, which indicates the contemporary college students' self-regulation awareness is stronger. They can consciously adjust themselves and scientifically manage their learning process. At the same times, it also reflects that foreign language educators and researchers in foreign language teaching field really regard learners as the center of teaching, regard cultivating learners' self-directed learning as the ultimate goal of teaching and achieve satisfactory result. The connection between old and new knowledge $(29,30)$, reasoning $(32$, $33,34)$ and migration $(31)$ has something in common: using the existing knowledge to understand and apply new language, seeking the inner connection of language input, thus making judgment and reasoning (O'Malley, 1989). This suggests that students often use their old knowledge/skills to help listening learning. Many foreign scholars have studied the importance of reasoning in learning. Rubin (1989) considers reasoning is the key process of successful learning. Therefore, three strategies is most frequently used, it is understandable. In addition the frequency of strategy 30 is not high. Strategy 30 is a negative strategy. The lower the ratio, the better the result.

The frequency of cognitive strategy "using the key words" (28) is the lowest. "Using key words" strategy is very popular in west countries while in China it is not. "Key words strategy" is to remember the words through associating image of a foreign word with a homonym in listeners' native language. Because Chinese and English belong to different language family, that it, most English words are polysyllabic words but most Chinese words are monosyllabic words, it is difficult to find a word that both has similar pronunciation and has meanings in Chinese. The further study should be made on whether "key words strategies" are fit for Chinese students. The function of another cognitive strategy "translation" in second language acquisition is not determined. It is generally believed that it has more negative effects than positive effects. This survey finds that students generally do not agree with practice that learning a foreign language depends too much on mother language, which is consistent with the research result of Wang Xiaowei (2003).

Students are reluctant to use "strategies of clarifying questions" $(48,49)$ and don't like to take the initiative to ask questions, which may be related to traditional teaching mode-students are regarded as a passive knowledge receiver and traditional culture of China. Chinese like maintaining face. According to the study of Reid Melton and Wang Chuming, Chinese students don't like collective learning and prefer learning alone. In a way, this was related to the education system of our country. Under the traditional education system, teachers and parents were strongly advocated competitive spirit and ignored the sharing of human intelligence which is again proved in this survey.

What is worth to explore is that "language consciousness strategy belonging to "learning about language" is neglected by students. Halliday (1987) in his article "Study Writing" pointed out that the language learning process is an organic whole of three aspects: learning language, learning about language and learning through language. Learning language is the study of language knowledge, including grammar and vocabulary, which is purely a grasp of the language itself. Learning about language is the understanding of nature, operation and function of language system. Learning about language is different from learning language in that it involves language learners' conscious reflection and understanding of language. In this sense, learning about language in essence refers to the meta-linguistic competence in linguistics field and it is a kind of language consciousness. Linguistics theory suggests not only there is no impassable gulf between language form and language consciousness, but also in many cases language form and language consciousness are closely related, even they 
are organic whole. As Palmer and Goetz (Goh, 1997) puts it: "what the learners know about the language itself has immeasurable influence on the whole learning process and even the learning result." This survey shows that students obviously lack of language awareness in foreign language learning which will influence the overall level of language learning.

\subsection{Teachers Strategies}

\subsubsection{Overall Situation of Teachers' Teaching Strategies}

Table 2. Overall situation of teachers' teaching listening strategies

\begin{tabular}{lll}
\hline & Mean value & Standard deviation \\
\hline Overall strategies & 3.1615 & .4213 \\
meta-cognitive strategies & 3.1795 & .9735 \\
cognitive strategies & 3.1663 & .9488 \\
social/affective strategies & 3.1387 & .9529 \\
\hline
\end{tabular}

From table 2 we can see the frequency of the teachers' teaching students listening strategies is 3.16. Although this frequency is higher than students' using strategies, 2.94, it also belongs to medium level. The degree of teachers' attention to social/affective strategies is not less than cognitive strategies. The mean values of these two listening strategies are very close. This result shows that emotional factors in the education are paid more and more attention to by teaches, which is also the emphasis of humanism psychology. Humanism psychology emphasizes to promote all-round development of people, therefore cognitive aspect and emotional aspect must be united. Cognition and emotion are not contradictive, opposite aspects. On the contrary, they supplement each other. If learners lack of emotion, their cognitive ability will be discounted (Arnold, 1999). Obviously the teachers in this survey construct their own teaching methods based on the whole person which means teachers not only make the students master the scientific knowledge effectively and improve ability, but also pay attention to cultivating students' good personality psychological quality and good emotional character.

\subsubsection{The Strategies Teachers Often Instruct and Often Neglect}

In order to further understand teachers' teaching strategy, we rank mean value of 46 teachers' listening strategies from high to low and the results show only mean value of 13 listening strategies is higher or equal to 3.5000 . These strategies are often used by teachers. They are self-management, reasoning, connection between old knowledge and new knowledge, notes-taking, listening to authentic corpus, selective attention, cultivating interest, language awareness, advanced organization, avoiding translation. Strategy with the highest mean value (4.0000) is "combination of listening and speaking" which means the application of language can help language learning. It is through the application of language that the information accepted can leave a deeper impression in the brain. Students can grasp the same information immediately next time they listen to it. To some degree, why students feel it very difficult to improve listening ability lies in the fact that they lack the opportunity to speak. The survey shows that university teachers have taken a new step on this issue. It's worth to mention that teachers often instruct self-management strategies and the cultivation of interest, which means teachers respect students' voluntary choice, and give full play to the subjective initiative, let students take on more autonomous learning responsibility. In addition, teachers often remind students avoiding using translation strategy which happens to have the same view that we advocate, thinking in English, eliminating the interference of mother tongue language.

The following five listening strategies are often neglected by teachers: using key words, classification, dividing meaningful groups, detailed planning, and analysis. The frequency of using key words is the lowest which is due to the same reason mentioned above. Directing students to make extracurricular detailed listening planning and arranging students to classify the knowledge they learned is not paid much attention to by teachers, which may be due to the reason that university teachers are different from secondary school teachers. Besides that, teachers mention in the questionnaires that listening class periods are not many, teachers can't put many listening theories into practice in listening classrooms, for example, teachers have no time to give a passage and let students make the stress and intonation, divide meaningful groups, etc. Therefore the teaching of listening strategies are limited by various factors. It needs to be further studied on how to teach and use listening strategies. 


\subsection{The Strategy Application Comparison between Students and Teachers}

Table 3. The strategy application comparison between students and teachers

\begin{tabular}{|c|c|c|c|c|c|c|}
\hline & teachers & & & students & & \\
\hline strategies teachers & Types of strategies & Items & Mean value & Types of strategies & Items & Mean value \\
\hline often instructed & Self-management & 12,9 & 3.8236 & Self-management & 15 & 4.1824 \\
\hline /strategies students & Reasoning & 27,28 & 3.5686 & Reasoning & $32,33,34$ & 3.8088 \\
\hline \multirow[t]{8}{*}{ often used } & $\begin{array}{l}\text { Connection between old and } \\
\text { new knowledge }\end{array}$ & 25 & 3.5000 & $\begin{array}{l}\text { Connection between old and } \\
\text { new knowledge }\end{array}$ & 29 & 3.6964 \\
\hline & Notes & 31 & 3.6061 & Taking notes & 35 & 3.7176 \\
\hline & Listen to authentic corpus & 39 & 3.7353 & Listening to authentic corpus & 43 & 3.6176 \\
\hline & Selective attention & 7,8 & 3.8089 & Selective attention & 8 & 3.6176 \\
\hline & Cultivating interest & 40 & 3.8235 & Cultivating interest & 44 & 3.5100 \\
\hline & Language consciousness & 2 & 4.0000 & Migration & 31 & 3.6687 \\
\hline & Organization in advance & 6 & 3.8788 & Self-monitoring & 16,17 & 3.7618 \\
\hline & Avoid translating & 34 & 3.6176 & & & \\
\hline strategies teachers & Key words & 24 & 2.3235 & Key words & 28 & 1.8393 \\
\hline often neglected & Classification & 20 & 2.4412 & Classification & 23 & 2.4882 \\
\hline /strategies students & Dividing meaningful groups & 35 & 2.3333 & Dividing meaningful groups & 40 & 2.4647 \\
\hline \multirow[t]{6}{*}{ seldom used } & Planning & 10 & 2.4706 & Planning & 11 & 2.3647 \\
\hline & Analysis & 22 & 2,3529 & Language consciousness & $1,2,4$ & 2.3423 \\
\hline & & & & Clarifying questions & 49 & 2.3176 \\
\hline & & & & Self-monitoring & 13 & 2.2882 \\
\hline & & & & Cooperative learning & 50,51 & 2.0009 \\
\hline & & & & Translation & 39 & 2.3559 \\
\hline
\end{tabular}

From table 3, we can see the most often instructed strategies by teachers are also the most commonly used strategies by students, including self-management, reasoning, the connecting old and new knowledge, taking notes, listening to authentic corpus, selective attention, cultivating interest etc. Translation belongs to negative strategies, so teachers often remind students not to use it. Its effects are reflected in the column in students' seldom used strategies. According to the statistics, $80 \%$ of the strategies often instructed by teachers are often used by students. From table three, it can be seen at the first fight that the number of strategies students commonly use and the number of strategies teachers often instruct are different. Only five strategies are often neglected by teachers while the 10 strategies are not commonly used by students. But among five strategies teachers neglect, four strategies are included in strategies students seldom use. So we can see strategies teachers instruct and strategies students often use are positively correlated with each other. Thus, we can draw a conclusion: listening strategies in college has the teachability in listening classroom.

Although students' using strategies and teachers' teaching strategies are closely related to each other to great extent, through analysis of variance, it is not difficult to find that on the application of social/affective strategies. There are obvious difference between teachers and students (table 4).

Table 4. Strategy variance analysis between teachers and students

\begin{tabular}{lllllll}
\hline & & number & Mean value & Standard deviation & T-Value & P-Value \\
\hline Overall strategies & students & 170 & 2.9439 & .38414 & .453 & .051 \\
& teachers & 34 & 3.1615 & .42134 & & \\
Meta-cognitive & students & 170 & 2.9333 & .42981 & .237 & .056 \\
strategies & teachers & 34 & 3.1795 & .41153 & & \\
Cognitive strategies & students & 170 & 3.0354 & .40227 & .384 & .702 \\
& teachers & 34 & 3.1663 & .50259 & & \\
Social/affective & students & 170 & 2.6949 & .5 .748 & .3 .221 & .003 \\
strategies & teachers & 34 & 3.1387 & .76527 & & \\
\hline
\end{tabular}

Teachers attach importance to both cognitive strategies and social/affective strategies while students obviously neglect the latter which indicates students in listening classroom seldom adopt sociallaffective strategies teachers instruct, which contribute to three reasons. Firstly, it is related to university students' psychology, namely, autism 
psychology. Contemporary college students have desire for independence and self-esteem. They are reluctant to communicate with teachers or classmates when they have difficulties so as to avoid damage their self-image. 2. Practical consciousness. Practical consciousness is an important characteristic of contemporary college students. They learn their professional knowledge and technical ability for stronger practical purpose. This practical consciousness definitely will be reflected in the listening strategies they adopt to improve their listening level. Cognitive strategy is directly related to the specific learning tasks, therefore its effects is obvious and direct. Although the efficiency of social/affective strategies is not less the former, they are indirect and implicit. By contrast, students are more likely to accept the cognitive strategies teachers instruct them and apply them to the process of listening learning. In addition to that, students are not commonly use social/affective strategy, which may be related to the nature of these two strategies themselves. We have just mentioned that cognitive strategy is direct, specific and operational, but social/affective strategy are mostly implicit mental activities, which need students to experience strategies themselves. Sometimes students use the automatically, but they may not be aware of that.

The students' social/emotional problem is a significant problem. The most recent study by scientists shows high IQ can not necessarily bring success, but people's EQ have great impact on a person's career success. Therefore social/affective strategies needs to be further studied.

\section{Conclusion}

This survey draws such conclusions:

(1) Strategies used by non-English majors in the process of listening learning belong to medium level. The frequency of the application of strategies from high to low is: cognitive strategy, meta-cognitive strategy and social/affective strategy.

(2) Strategies instructed by teachers also belong to medium level. Among three main strategies, the frequency of the application of meta-cognitive strategy is the highest, while the frequency of the application of cognitive and social/affective strategies is equal.

(3) In general, strategies teachers instruct and strategies student use are positively correlated. But there is a certain gap on the application of social/affective strategies. Teachers attach equal importance to both cognitive strategy and social/affective strategies, but students seldom apply social/affective strategies.

Limitation and suggestions to the listening strategy teaching and learning:

First, teachers should make an effort to help students to enhance listening strategy consciousness, help to improve students' frequency and range of application of listening strategies, especially improve students' awareness of social/affective strategies.

Second, teachers have taken a new step in teaching concept, but it still needs to be explored how to make specific teaching strategy more productive.

Finally, this listening strategy study is a synchronic study. The results of the survey is only the stationary state at some point, therefore the author can't grasp the dynamic process, what influence learners' choice and application of learning strategies have on their language development. The author hopes more and more researchers will try to understand the dynamic process of learners' listening learning process through diachronic study.

\section{References}

Anderson, J. R. (1981). Cognitive Skills and their Acquisition. Hillsdale, NJ: Lawrence Erlbaum.

Anderson, J. R. (1985). Cognitive Psychology and its Implication. New York: W. H. Freeman.

Anderson, J. R., \& Lynch. (1988). Listening. Oxford: Oxford University Press.

Anserson, J. R. (1983). Architecture of Cognition. Cambridge, MA: Harvard University Press.

Arnold, J. (1999). Affect in Language Learning. Cambridge: Cambridge University Press.

Brown A. L. (1982). Introducing Strategic Learning from Texts by Means of Informed, Self-control Training. Topic in Learning and Learning Disabilities, 2.

Chamot, A. U. (1987). Learning strategies of ESL students. In Wenden (Ed.), Learner Strategies in Language Learning. Great Brain: Prentice Hall.

Ellis, R. (1994). The Study of Second Language Acquisition. Oxford: Oxford University Press.

Goh, C. (1997). Metacognitive Awareness and Second Language Listeners. ELT Journal, 4. 
Halliday, M. A. K. (1987). Study Writing. Cambridge: Cambridge Press.

Jane, A. (1999). Affect in Language Learning. Cambridge: Cambridge University Press.

Nisbet, N., \& Shucksmith, J. (1986). Learning Strategy. Boston: Routledge and Kegan Paul.

O’Malley, J. M., \& Chamot, A. U. (1990). Learning Strategies in Second Language Acquisition. Cambridge: Cambridge University Press.

O’Malley, J. M., Chamot, A. U., \& Kupper, L. (1989). Listening comprehension strategies in second language acquisition. Applied Linguistics, 11(4).

Oxford, R. L. (1990). Language Learning Strategies: What Every Teacher Should Know. New York: Newberry House.

Rubin, J. (1981). Study of Cognitive Process in Second Language Learning. Applied Linguistics, (2).

Wang, X. W. (2003). A Comparison Study of English Learners' learning Strategies in Different Stages. Higher Education in Heilongjiang Province, (2).

\section{Appendix A}

\section{Students' Listening Strategy Questionnaire}

\section{Part A. Meta-cognitive Strategy}

1. In the usual learning process, I pay attention to accumulation of language knowledge, such as, pronunciation and intonation, liaison, loss of blasting, weakening, assimilation, stress, rising and falling tone to help improve listening ability.

2. I often think about knowledge on the listening learning, for example, how many steps are listening process divided? What are the factors that influence the listening?

3. To help improve your listening, I strive to do a lot of reading practice after class.

4. I try to use English to communicate. The output of the language makes the information heard makes a deep impression in my mind, namely, application of language can help language learning.

5. I often compare English language phenomena, such as the sentence structure, expression, etc. with that of Chinese in order to find out the similarities and difference to help myself understand better English better.

8. When listening to the English, I try to understand every word.

11. Not only do I have an overall listening plan, but I make a detailed arrangement to every day's and every week's listening plan and record the progress I make every time.

13. After class I will review the listening materials in a planned way.

15. When listening to English, I'll skip the new words or difficult sentences and continue to listen.

16. In the process of listening, I pay attention to whether I have distraction from the listening material. If I do so, I will try to focus on the current task.

17. When listening, if I find the mistakes I make, I'll find out the reasons.

\section{Part B. Cognitive Strategy}

23. After class, I will classify and categorize the words, terminology and concept I have learned.

28. When listening, I try to remember the new English words through relating the pronunciation of Chinese words.

32. In the process of listening, when encountering new words, I'll use all possible ways to find clues to guess the general meaning, such as through the context clue.

33. In the process of listening, I often make reasoning through discourse makers, such as but, because, therefore, however etc.

34. In the process of listening, I take notes while listening. I try to write down the important information.

39. When listening, I prefer to translating the information I heard into Chinese in my mind.

40. When listening, I know how to divide meaning groups and listen according to these groups.

43. I often have access to the authentic and national English corpora through watching English movies, and 
sitcoms.

\section{Part C. Social/affective Strategy}

44. I choose the learning ways that I like to study outside the classroom, such as listening to music, watching English TV, listening to the radio.

48. While listening, I consult classmates and teachers when I meet some difficult problems.

49. I not only question myself about the difficult point I can't understand and but also through question I design to get more information from the speakers.

50. In listening study, I often communicate with teachers, classmates to share some common information with them, and at the same time test learning effects of myself.

51. I like to find one or several partners to learn together.

\section{Appendix B}

\section{Teachers' Teaching Strategy Questionnaire}

\section{Part A. Meta-cognitive Strategy}

2. In listening class, I often combine the listening and speaking, that it, the information heard can leave a deeper impression through speaking, namely, language application can help language learning.

6. Before making students listen to the material, I introduce some background information, related terms and guide them to preview the new words, illustrations and exercises.

7. According to different listening tasks, I guide students to use different listening skills to understand the listening materials.

8. Before listening let students understand listening purposes, such as listen to the general meaning or important details, etc.

9. When encountering difficult words or sentences, guide students to skip the them and continue to listening.

10. Help students to develop extracurricular listening program, establish listening exercise goal, and encourage students to report on what they hear regularly.

12. Motivate the students to create opportunities to practice listening himself, such as taking advantage of oral English class or participating in the English corner, etc.

20. Assign students to classify and categorize the words, terminology, concept they have learned.

\section{Part B. Cognitive Strategy}

22. Analyze different types of listening with students, summarize the general rules, for example, when listening to the news reports, students should pay attention to when, where, why.

24. Through contrastive analysis, teach students to use similar pronunciation of Chinese words to remember new English words which appear in the listening process.

25. I not only teach students new knowledge, but also teach them to understand the listening materials through analyzing the connection between old and new knowledge and common sense.

27. Analyze some pragmatic functions of discourse marker, such as but, because, therefore, however to help students to reason and make judgments.

28. Before listening, teach students to predict the material content according to titles and the questions to be answered.

29. In the process of listening, sometimes pause and let students to forecast the following content according the above content.

31. Before and after listening organize students to discuss how to take notes. In the process of listening, let students write down information they think is important.

34. When listening English materials, remind students not to translate every word into Chinese in their minds.

35. Sometimes give students some model essay in class, let them mark the stress and intonation, divide meaningful groups to improve listening comprehension ability.

39. Introduce and play some English movie, situational comedies to let the students contact the most real and natural English. 


\section{Part C. Social/affective Strategy}

To guide students to choose their interested methods to learn English outside their classroom, such as listening to music, watching English TV, listen to the radio, etc.

\section{Copyrights}

Copyright for this article is retained by the author(s), with first publication rights granted to the journal.

This is an open-access article distributed under the terms and conditions of the Creative Commons Attribution license (http://creativecommons.org/licenses/by/4.0/). 